\title{
Genetic diversity and relationship of Indian cattle inferred from microsatellite and mitochondrial DNA markers
}

Rekha Sharma*, Amit Kishore, Manishi Mukesh, Sonika Ahlawat, Avishek Maitra, Ashwni Kumar Pandey and Madhu Sudan Tantia

\begin{abstract}
Background: Indian agriculture is an economic symbiosis of crop and livestock production with cattle as the foundation. Sadly, the population of indigenous cattle (Bos indicus) is declining ( $8.94 \%$ in last decade) and needs immediate scientific management. Genetic characterization is the first step in the development of proper management strategies for preserving genetic diversity and preventing undesirable loss of alleles. Thus, in this study we investigated genetic diversity and relationship among eleven Indian cattle breeds using 21 microsatellite markers and mitochondrial D loop sequence.
\end{abstract}

Results: The analysis of autosomal DNA was performed on 508 cattle which exhibited sufficient genetic diversity across all the breeds. Estimates of mean allele number and observed heterozygosity across all loci and population were $8.784 \pm 0.25$ and $0.653 \pm 0.014$, respectively. Differences among breeds accounted for $13.3 \%$ of total genetic variability. Despite high genetic diversity, significant inbreeding was also observed within eight populations. Genetic distances and cluster analysis showed a close relationship between breeds according to proximity in geographic distribution. The genetic distance, STRUCTURE and Principal Coordinate Analysis concluded that the Southern Indian Ongole cattle are the most distinct among the investigated cattle populations. Sequencing of hypervariable mitochondrial DNA region on a subset of 170 cattle revealed sixty haplotypes with haplotypic diversity of 0.90240 , nucleotide diversity of 0.02688 and average number of nucleotide differences as 6.07407. Two major star clusters for haplotypes indicated population expansion for Indian cattle.

Conclusions: Nuclear and mitochondrial genomes show a similar pattern of genetic variability and genetic differentiation. Various analyses concluded that the Southern breed 'Ongole' was distinct from breeds of Northern/ Central India. Overall these results provide basic information about genetic diversity and structure of Indian cattle which should have implications for management and conservation of indicine cattle diversity.

Keywords: Conservation, Diversity, Genetic relationship, Indian cattle, Microsatellite markers, Mitochondrial DNA, Population structure

\section{Background}

India is home to the largest cattle population (13.1\% of world's cattle population) in the world which constitutes $37.3 \%$ of its total livestock [1]. Indian zebu cattle (Bos indicus) evolved over centuries under low levels of selection followed in traditional animal husbandry. As a result, Indian cattle adapted to harsh native environment, resistance to tropical diseases and external parasites and

\footnotetext{
*Correspondence: rekvik@gmail.com

Core lab (Network Project Unit), National Bureau of Animal Genetic Resources, G T Road, Karnal 132001, Haryana, India
}

sustenance on low quality roughages and grasses. A large and divergent range of agro-ecological zones in India have helped to develop number of cattle populations. The state of world's animal genetic resources, SoW-AnGR listed a total of 60 local, eight regional trans-boundary and seven international trans-boundary cattle breeds from India [2]. Among these very few are maintained for milk production (Sahiwal, Gir, Rathi and Sindhi), some are dual-purpose breeds (Deoni, Hariana, Kankrej and Tharparkar) while the rest are draft breeds, maintained by farmers for producing bullocks. With the modernization of agriculture and 
sub-division of land holdings, bullock power in Indian agriculture is losing its importance. Thus, many of the draft breeds are under severe neglect resulting in continuous decline of indigenous cattle population [1]. In addition, introduction of highly productive breeds and demographic pressure are also contributing to the loss of valuable traits or decrease in population of local breeds.

Genetic characterization of breeds allows evaluation of genetic variability, a fundamental element in working out breeding strategies and genetic conservation plans. Molecular markers have revolutionized our ability to characterize genetic variation and rationalize genetic selection [3]. Markers have been comprehensively exploited to access genetic variability as they contribute information on every region of the genome, regardless of the level of gene expression. Employment of microsatellite markers is one of the most powerful means for studying the genetic diversity, calculation of genetic distances, detection of bottlenecks and admixture because of high degree of polymorphism, random distribution across the genome, codominance and neutrality with respect to selection [4]. Mitochondrial DNA (mtDNA) is also considered to be a good tool for genetic diversity and evolutionary studies due to near-neutrality, maternal inheritance and clock-like nature of its substitution rate [5]. The Displacement region (D-loop) is proven to be a particularly useful genetic marker because it evolves much rapidly than the coding region of the mtDNA [6]. Direct comparisons between mtDNA and microsatellite loci can be very informative for population diversity and genetic structure, as evolutionary forces affect each class of marker differently [7].

Considering the importance of cattle in Indian agriculture, few efforts have been made to evaluate the genetic diversity and relationship in Indian cattle using microsatellite markers [8-12]. However, ecomprehensive knowledge of the breed characteristics, including within-and betweenbreed genetic diversity which will result in complete representation possible of biological diversity is required to facilitate effective management. Thus, a deeper knowledge of the genetic diversity and population structure of Indian cattle can provide a rational basis for the need of conservation and possible use of native breeds as genetic resources to meet potential future demand of adaptation to changing environment or production needs. Therefore, the present investigation was undertaken to quantify the genetic diversity and relationship between eleven cattle breeds of India.

The objectives of this study were to use microsatellite markers and mitochondrial DNA control region polymorphisms to characterize the within-breed genetic diversity, to establish breed relationships and to assess their population structure. The use of molecular information supplied by nuclear and mtDNA markers is aimed to provide a rational basis for suitable strategies of management and conservation.

\section{Method}

\section{Sample collection and DNA extraction}

No animal experiments were performed in this study, and, therefore, approval from the ethics committee was not required. Blood samples were collected with the help of veterinary doctors from respective State Animal Husbandry Department. In total, 508 animals from 11 different cattle breeds (Bachaur-50, Gangatiri-50, Kherigarh48, Kenkatha-48, Ponwar-39, Shahabadi-48, Purnea-47, Mewati-48, Gaolao-48, Hariana-40 and Ongole-42) were sampled from Northern, Central and Southern India (Fig. 1). Samples of the populations included in this study represented animals of the original autochthonous phenotype. To ensure random sampling, animals were selected from different villages of habitat while avoiding closely related individuals on the basis of detailed interview with owners. Blood samples were collected from jugular vein in $10 \mathrm{ml}$ vacuitainer tubes with EDTA as anticoagulant and were stored at $-20{ }^{\circ} \mathrm{C}$ until DNA extraction. Genomic DNA was isolated from blood using Phenol-chloroform method as described by Sambrook and Russel [13].

\section{Microsatellite polymorphism}

DNA samples were amplified by PCR in correspondence with the selected panel of 21 bovine specific loci. The loci were chosen, according to ISAG/FAO recommendation aiming to analyze high polymorphic markers spread all over the genome and with the ability to co-amplify in PCR reactions [14]. The fluorochrome labeled (FAM, NED, PET\& VIC) primers were synthesized by Applied Biosystems (Table 1). For amplification, 50-100 ng of genomic DNA was added to a reaction mixture containing $50 \mathrm{pMol}$ of primer-forward and reverse, $200 \mu \mathrm{M}$ of each dNTPs, $1.5 \mathrm{mM}$ of $\mathrm{MgCl}_{2}$ and $0.5 \mathrm{U}$ of Taqpolymerase in a final volume of $25 \mu \mathrm{l}$. All the microsatellites were amplified by a BioRADthermal cycler at the following conditions: initial denaturation of $1 \mathrm{~min}$ at $95{ }^{\circ} \mathrm{C}$, 30 cycles of $1 \mathrm{~min}$ at $95{ }^{\circ} \mathrm{C}, 1 \mathrm{~min}$ at $\mathrm{T}^{\circ} \mathrm{C}$ (optimum annealing temperature of each primer) and $1 \mathrm{~min}$ at $72{ }^{\circ} \mathrm{C}$ and a final extension of $5 \mathrm{~min}$ at $72{ }^{\circ} \mathrm{C}$. Amplified fragments were separated by capillary electrophoresis using an ABI PRISM 3100 automatic sequencer (Applied Biosystems, Foster City, CA, USA) and allele sizing was accomplished by using the internal size standard GeneS$\operatorname{can}^{\mathrm{Tm}}-500 \mathrm{LIZ}^{\mathrm{sm}}$. Fluorescently labeled fragments were detected and sized using GeneMapper software (version 3.7, Applied Biosystems, USA). Stutter related scoring error, often seen in dinucleotide repeats, was absent and alleles could be scored unambiguously.

\section{Microsatellite statistical analysis}

GENALEX 6.2 software [15] was used to estimate basic population genetic descriptive statistics for each marker and population: gene frequency, observed number of 


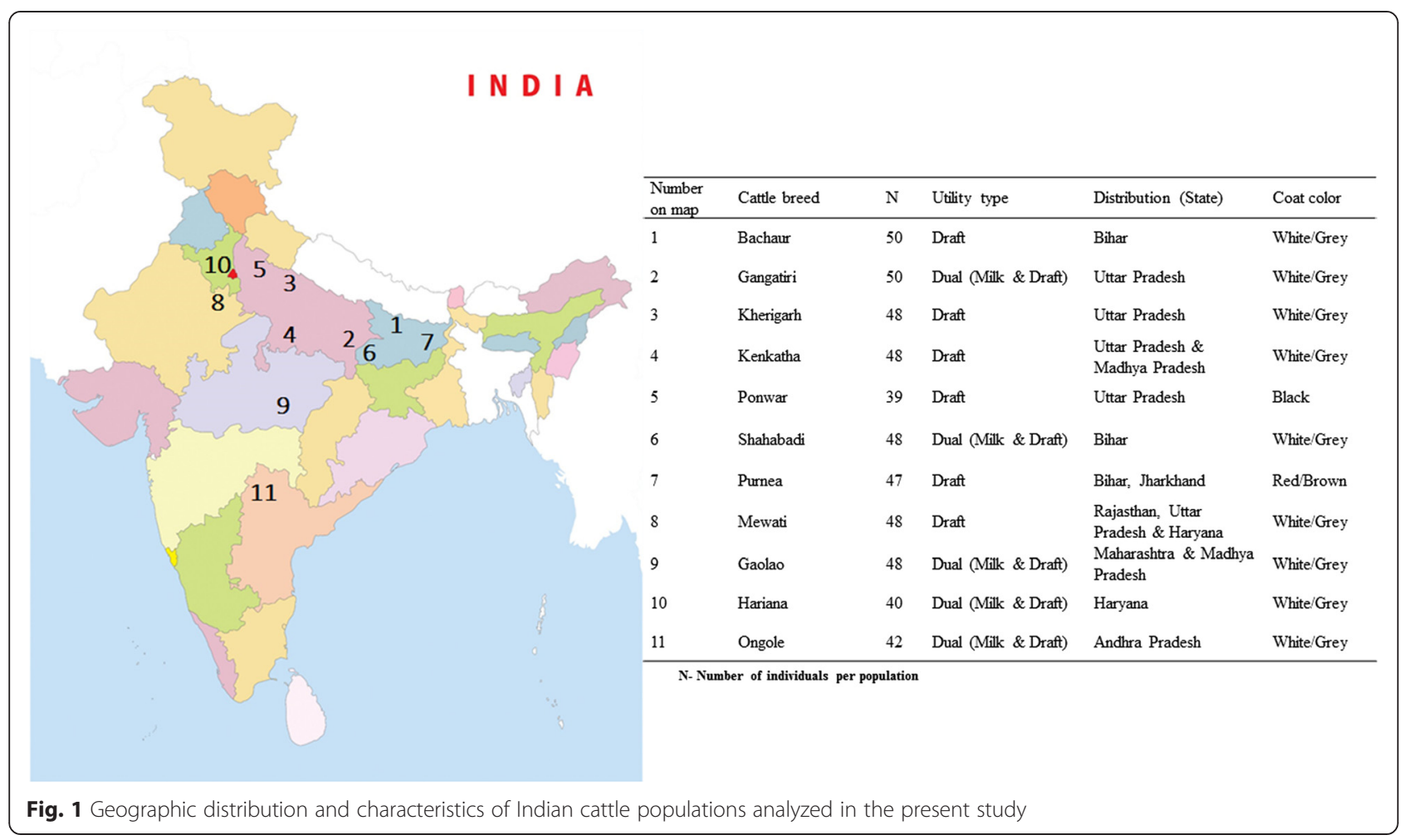

alleles (No), number of private alleles, effective number of alleles ( $\mathrm{Ne}$ ), observed ( $\mathrm{Ho}$ ) and expected heterozygosity (He) and Analysis of Molecular Variance (AMOVA). The distribution of genetic variability between various breeds was studied by analyzing the Wright's $F$-statistics $\left(F_{I S}(f), F_{S T}(\theta)\right.$ and $F_{I T}(F)$ and Nei's [16] standard genetic distances among populations. Pair wise matrix of the genetic distances was then used to obtain Neighborjoining $(\mathrm{NJ})$ tree which was visualized using the software TreeView [17]. Bootstraps of 1000 replicates were performed in order to test the robustness of tree topology using the Phylip software [18]. The software GENEPOP version 3.4 [19] was used to perform global and per locus/ per population Hardy-Weinberg equilibrium (HWE) test, and to test for genotypic linkage disequilibrium (LD). Markov Chain method was employed with 1000 dememorization steps, 100 batches and 10,000 iterations. An alternative model based on Bayesian clustering analysis was used to infer how many clusters or sub-populations (K) were most appropriate for interpreting the data without prior information on the number of locations at which the individuals were sampled as implemented in STRUCTURE v2.2 [20]. Simulation was performed using a burn-in period of 50,000 rounds followed by 30,000 MCMC (Marcov Chain Monte Carlo) iterations. Independent runs of $\mathrm{K}$ were performed from 1 to 15 clusters and were repeated five times to check the consistency of the results. To choose the optimal K, posterior probability was calculated for each value of $\mathrm{K}$ using the mean estimated log-likelihood of $\mathrm{K}, \mathrm{L}(\mathrm{K})$. Following Evanno et al. [21], delta $\mathrm{K}$ was calculated for each tested value of $\mathrm{K}$ (except for the maximum $\mathrm{K}$ tested), which is an ad-hoc statistic that is based on the second derivative of 'the likelihood function with respect to K, L" (K). Graphic representation of these statistics was obtained using the web-based STRUCTURE Harvester software [22]. Principal Coordinate Analysis (PCoA) was employed for deciphering the population structure as implemented in GENALEX 6.2 software [15] and Principal Component Analysis (PCA) by XLSTAT version 2015.1.03.16133; Copyright Addinsoft 1995-2014 software.

\section{Mitochondrial DNA sequencing}

The non-coding D-loop region was amplified by PCR, using primer pair (5'-TAGTGCTAATACCAACGGCC3', 5' -AGGCATTTTCAGTGCCTTGC-3'), as described by Suzuki et al. [23]. The D-loop primers yielded a PCR product of $1142 \mathrm{bp}$ representing the whole D-loop and flanking sequence at both ends. Polymerase Chain Reaction (PCR) was carried out on about 50-100 ng genomic DNA in a $25 \mu \mathrm{l}$ reaction volume using i-cycler (BioRAD, USA). The reaction mixture consisted of $200 \mu \mathrm{M}$ of each dNTPs, $1.5 \mathrm{mM} \mathrm{MgCl} 2$, 50pmol primer, $0.5 \mathrm{U}$ Taq polymerase (Bangalore GeneiPvt Ltd., Bangalore, India) and Taq buffer. Negative controls (lacking template DNA) were included in all reactions, and produced no products. The PCR reaction cycle was accomplished by denaturation for $6 \mathrm{~min}$ at $94{ }^{\circ} \mathrm{C}, 30$ cycles of $94{ }^{\circ} \mathrm{C}$ for 
Table 1 Characteristics of 21 microsatellite loci used in present study

\begin{tabular}{|c|c|c|c|c|c|c|}
\hline Primers & Primer sequences $\left(5^{\prime}-3^{\prime}\right)$ & Forward label & Set & Annealing temperature & Product size (bp) & Total number of alleles \\
\hline \multirow[t]{2}{*}{ BM1824 } & F-gagcaaggtgtttttccaatc & VIC & 4 & $58^{\circ} \mathrm{C}$ & $176-196$ & 11 \\
\hline & R-cattctccaactgcttccttg & & & & & \\
\hline \multirow[t]{2}{*}{ CSSM08 } & F-cttggtgttactagccctggg & $\mathrm{VIC}$ & 3 & $55^{\circ} \mathrm{C}$ & $182-200$ & 8 \\
\hline & R-gatatatttgccagagattctgca & & & & & \\
\hline \multirow[t]{2}{*}{ CSSM33 } & F-cactgtgaatgcatgtgtgtgagc & NED & 5 & $58^{\circ} \mathrm{C}$ & 144-188 & 21 \\
\hline & R-cccatgataagagtgcagatgact & & & & & \\
\hline \multirow[t]{2}{*}{ CSSM66 } & F-acacaaatcctttctgccagctga & FAM & 4 & $60^{\circ} \mathrm{C}$ & $167-207$ & 19 \\
\hline & R-aatttaatgcactgaggagcttgg & & & & & \\
\hline \multirow[t]{2}{*}{$\mathrm{ETH} 10$} & F-gttcaggactggecctgctaaca & NED & 1 & $58^{\circ} \mathrm{C}$ & $185-221$ & 14 \\
\hline & R-cctccageccactttctcttctc & & & & & \\
\hline \multirow[t]{2}{*}{$\mathrm{ETH} 225$} & F-gaacctgectctcctgcattgg & VIC & 4 & $64^{\circ} \mathrm{C}$ & 134-162 & 13 \\
\hline & R-actctgcctgtggccaagtagg & & & & & \\
\hline \multirow[t]{2}{*}{ ETH3 } & F-gatcaccttgccactatttcct & NED & 4 & $57^{\circ} \mathrm{C}$ & $90-124$ & 16 \\
\hline & R-acatgacagccagctgctact & & & & & \\
\hline \multirow[t]{2}{*}{ HEL09 } & F-cccattcagtcttcagaggt & FAM & 5 & $59^{\circ} \mathrm{C}$ & 140-182 & 17 \\
\hline & R-cacatccatgttctcaccac & & & & & \\
\hline \multirow[t]{2}{*}{ HEL5 } & F-gcaggatcacttgttaggga & VIC & 3 & $55^{\circ} \mathrm{C}$ & 137-195 & 25 \\
\hline & R-agacgttagtgtacattaac & & & & & \\
\hline \multirow[t]{2}{*}{ ILSTS06 } & F-tgtctgtatttctgctgtgg & FAM & 5 & $58^{\circ} \mathrm{C}$ & $275-303$ & 14 \\
\hline & R-acacggaagcgatctaaacg & & & & & \\
\hline \multirow[t]{2}{*}{ ILSTS11 } & F-gcttgctacatggaaagtge & NED & 1 & $58^{\circ} \mathrm{C}$ & $249-273$ & 10 \\
\hline & R-ctaaaatgcagagccctacc & & & & & \\
\hline \multirow[t]{2}{*}{ ILSTS34 } & F-aagggtctaagtccactggc & VIC & 5 & $59^{\circ} \mathrm{C}$ & $138-212$ & 37 \\
\hline & R-gacctggtttagcagagagc & & & & & \\
\hline \multirow[t]{2}{*}{ ILSTS33 } & F-tattagagtggctcagtgcc & PET & 3 & $55^{\circ} \mathrm{C}$ & $131-163$ & 16 \\
\hline & R-atgcagacagttttagaggg & & & & & \\
\hline \multirow[t]{2}{*}{ INRA05 } & F-caatctgcatgaagtataaatat & FAM & 2 & $54^{\circ} \mathrm{C}$ & $130-148$ & 9 \\
\hline & R-cttcaggcataccctacacc & & & & & \\
\hline \multirow[t]{2}{*}{ INRA35 } & F-atcctttgcagectccacattg & FAM & 3 & $54^{\circ} \mathrm{C}$ & 80-142 & 24 \\
\hline & R-ttgtgctttatgacactatccg & & & & & \\
\hline \multirow[t]{2}{*}{ INRA63 } & F-atttgcacaagctaaatctaacc & PET & 2 & $54^{\circ} \mathrm{C}$ & $162-190$ & 14 \\
\hline & R-aaaccacagaaatgcttggaag & & & & & \\
\hline \multirow[t]{2}{*}{ MM12 } & F-caagacaggtgtttcaatct & PET & 4 & $52^{\circ} \mathrm{C}$ & $88-134$ & 21 \\
\hline & R-atcgactctggggatgatgt & & & & & \\
\hline \multirow[t]{2}{*}{ MM8 } & F-cccaaggacagaaaagact & NED & 2 & $55^{\circ} \mathrm{C}$ & $114-144$ & 12 \\
\hline & R-ctcaagataagaccacacc & & & & & \\
\hline \multirow[t]{2}{*}{ TGLA122 } & F-ccctcctccaggtaaatcagc & VIC & 1 & $58^{\circ} \mathrm{C}$ & 133-179 & 20 \\
\hline & R-aatcacatggcaaataagtacatac & & & & & \\
\hline \multirow[t]{2}{*}{ TGLA227 } & F-cgaattccaaatctgttaatttgct & PET & 2 & $55^{\circ} \mathrm{C}$ & $67-119$ & 17 \\
\hline & R-acagacagaaactcaatgaaagca & & & & & \\
\hline \multirow[t]{2}{*}{ TGLA53 } & F-gctttcagaaatagtttgcattca & FAM & 1 & $58^{\circ} \mathrm{C}$ & $142-184$ & 21 \\
\hline & R-atcttcacatgatattacagcaga & & & & & \\
\hline
\end{tabular}


$45 \mathrm{~s}, 60{ }^{\circ} \mathrm{C}$ for $30 \mathrm{~s}, 72{ }^{\circ} \mathrm{C}$ for $60 \mathrm{~s}$, and finally extension at $72{ }^{\circ} \mathrm{C}$ for $6 \mathrm{~min}$, before cooling to $4{ }^{\circ} \mathrm{C}$ for $10 \mathrm{~min}$. The size of amplification product was checked by loading $5 \mu \mathrm{L}$ PCR product ontoa $1.8 \%$ agarose gel containing $0.5 \mu \mathrm{L} / \mathrm{mL}$ ethidium bromide. The product was purified usinga QIA quick PCR purification kit (Qiagen, Hilden, Germany). Purified product was labeledusing the BigDye Terminator 3.1 Cycle sequencing kit (Applied Biosystems, Foster City, CA,USA) and sequenced directly using an ABI3100 Prism automatic DNA sequencer followingmanufacturer instructions. The primers used for sequencing were the same as those used in the PCR. Both strands of PCR product were completely sequenced. All finalsequences were determined from both strands for verification.

\section{Mitochondrial DNA statistical analysis}

The DNA sequences were edited manually using EDITSEQ (DNASTAR) and the MegAlign program (DNASTAR) was used for multiple alignments. Sites representing a gap in any of the aligned sequences were excluded from the analysis. We compared 60 D-loop haplotypes of a 230-bp hypervariable region-I (HVR-I) fragment of mtDNA control region obtained from 170 cattle from India. Mean number of pairwise differences and nucleotide diversity $(\pi)$ within cattle breeds, nucleotide divergence between breeds and haplotype diversity $\left(\mathrm{H}_{\mathrm{d}}\right)$ of breeds were calculated by Arlequin 3.1 [24]. The Neighbour-joining treebased on the HYR-I sequences was reconstructed using MEGA software [25]. Network analysis was used to visualize the spatial distribution of the sequence variation among the different mtDNA haplotypes. Network profiles among haplotypes were constructed by median-joining networks (NETWORK 4.5; http:// www.fluxus-engineering.com/sharenet.htm), resolving the reticulations through a maximum parsimony criterion [26].

\section{Results}

\section{Microsatellite and Mitochondrial genetic variability}

Genetic status and diversity of indigenous cattle populations of India was established using nuclear (microsatellite markers) and mitochondrial polymorphisms. All microsatellite markers used in this study were successfully amplified in five multiplex sets designed with consideration for annealing temperature, product size and specific dye label in all the populations (Table 1). The genotype data generated in present study showed that significant amount of genetic variation is maintained in indicine cattle populations. All the markers were found to be polymorphic in each of the eleven populations analyzed. Considering all the populations, majority of the markers were in HardyWeinberg Equilibrium (HWE). Deviations from HWE were statistically significant $(\mathrm{P}<0.01)$ in 5 (Bachaur, Gaolao), 4 (Ongole, Purnea, Kenkatha, Kherigarh), 3 (Hariana, Mewati, Ponwar, Shahabadi) and 2 (Gangatiri) loci. The level of variations depicted by number of alleles at each locus serves as a measure of genetic variability having direct effect on differentiation of breeds within a species [27]. Thus, FAO has specified a minimum of four different alleles per locus for evaluation of genetic differences between breeds. By this criterion, all the 21 microsatellite loci showed ample polymorphism for evaluating within breed genetic variability and exploring genetic differences between breeds as four or more alleles were observed at each loci.

A total of 359 alleles were detected with ILSTS34 presenting the highest number of alleles per locus (37) while CSSM08 was least (8 alleles) polymorphic. The average observed number of alleles per locus ranged from $6.571 \pm 0.732$ in Hariana to $10.619 \pm 0.824$ in Shahabadi cattle with the mean allele number across all the loci of $8.784 \pm 0.25$ (Table 2). The average effective number of alleles in a population varied from $3.374 \pm$ 0.329 (Hariana) to $4.745 \pm 0.532$ (Shahabadi). Lower values of expected number of alleles as compared to observed number of alleles in all the populations suggested that there were many low frequency alleles in the populations. The private alleles, confined to one population only, ranged between none (Bachaur, Gangatiri, Kenkatha, Ponwar) and 24 (Ongole). Most of them were rare alleles with allele frequencies $<5 \%$ at each locus in each population. But still there were 24 private alleles at all loci across all populations with allele frequencies $>5 \%$, and occurrence of these alleles can lead towards genetic signatures for a particular population. No significant linkage disequilibrium was detected between any two of these loci which were located on a single chromosome, and thus all were retained for diversity and differentiation analysis.

Estimates of observed heterozygosity including all loci and populations $(0.653 \pm 0.01)$ confirmed the remarkable level of diversity in the Indian cattle. Among populations, observed heterozygosity ranged from $0.459 \pm 0.07$ to $0.724 \pm 0.036$ with the lowest value found in Ongole cattle and the highest in Kenkatha cattle (Table 2). Observed heterozygosity was lower than the expected heterozygosity in Bachaur, Ponwar, Shahabadi, Purnea, Mewati, Gaolao, Hariana and Ongole cattle populations. Analysis of $\mathrm{F}_{\mathrm{IS}}$ evidenced heterozygote deficiency which was highest in Ongole $(22.1 \%)$ and lowest in Ponwar (1.4\%).

A fragment of 230 bp hypervariable region-I (HVR-I) of the non-coding mtDNA control region was unambiguously explored resulting in identification of 223 variable sites. Consequently, 60 haplotypes were identified with haplotypic diversity of 0.90240 (Table 3). The mtDNA control region haplotype sequences were deposited in GenBank [KP223257- KP223282]. An overall estimate for population indices revealed nucleotide diversity of 0.02688 and average number of nucleotide 
Table 2 Genetic diversity indices (Average) across 11 Indian cattle breeds with 21 microsatellite markers

\begin{tabular}{llllll}
\hline Cattle population & $\mathrm{Na}$ & $\mathrm{Ne}$ & $\mathrm{Ho}$ & $\mathrm{He}$ & $\mathrm{F}_{\text {is }}$ \\
\hline Bachaur & $9.476 \pm 0.752$ & $4.186 \pm 0.440$ & $0.694 \pm 0.038$ & $0.705 \pm 0.030$ & 0.017 \\
Gangatiri & $9.190 \pm 0.716$ & $4.117 \pm 0.436$ & $0.709 \pm 0.034$ & $0.702 \pm 0.030$ & $-0.010^{*}$ \\
Kherigarh & $9.238 \pm 0.889$ & $4.086 \pm 0.444$ & $0.704 \pm 0.035$ & $0.700 \pm 0.029$ & -0.002 \\
Kenkatha & $9.000 \pm 0.878$ & $4.123 \pm 0.409$ & $0.724 \pm 0.036$ & $0.703 \pm 0.030$ & $-0.028^{*}$ \\
Ponwar & $8.857 \pm 0.804$ & $4.329 \pm 0.518$ & $0.696 \pm 0.039$ & $0.702 \pm 0.031$ & 0.014 \\
Shahabadi & $10.619 \pm 0.824$ & $4.745 \pm 0.532$ & $0.713 \pm 0.035$ & $0.735 \pm 0.027$ & $0.034^{*}$ \\
Purnea & $8.905 \pm 0.771$ & $4.072 \pm 0.402$ & $0.681 \pm 0.040$ & $0.706 \pm 0.027$ & $0.042^{*}$ \\
Mewati & $7.762 \pm 0.730$ & $3.451 \pm 0.425$ & $0.579 \pm 0.049$ & $0.634 \pm 0.043$ & $0.098^{*}$ \\
Gaolao & $9.143 \pm 0.762$ & $4.176 \pm 0.383$ & $0.616 \pm 0.034$ & $0.717 \pm 0.026$ & $0.146^{*}$ \\
Hariana & $6.571 \pm 0.732$ & $3.374 \pm 0.329$ & $0.604 \pm 0.052$ & $0.632 \pm 0.049$ & $0.042^{*}$ \\
Ongole & $7.667 \pm 1.107$ & $4.223 \pm 0.698$ & $0.459 \pm 0.068$ & $0.594 \pm 0.078$ & $0.221^{*}$ \\
Mean \pm SE & $8.784 \pm 0.252$ & $4.082 \pm 0.139$ & $0.653 \pm 0.014$ & $0.685 \pm 0.012$ & $0.048 \pm 0.017$ \\
\hline
\end{tabular}

Na- Observed number of alleles, Ne-Expected number of alleles, Ho-Observed heterozygosity; He-Expected heterozygosity, $\mathrm{F}_{\mathrm{is}}{ }^{-}$Inbreeding coefficient, * $(p<0.05)$

differences as 6.07407. These indices indicated sufficient mtDNA diversity amongst the analyzed breeds. Haplotype diversity $\left(\mathrm{H}_{\mathrm{d}}\right)$ was high in all the populations, ranging from 0.80526 (Hariana) to 0.96429 (Ponwar).

\section{Population differentiation}

Results of F-statistics for each of the 21 loci across populations are presented in Table 4. The global deficit of heterozygotes across populations $\left(\mathrm{F}_{\mathrm{IT}}\right)$ amounted to $17.5 \%(P<0.001)$. An overall significant deficit of heterozygotes $\left(\mathrm{F}_{\mathrm{IS}}\right)$ of $4.9 \%$ occurred in the analyzed loci because of inbreeding within populations. The multi-locus $\mathrm{F}_{\mathrm{ST}}$ values of breed differentiation indicated that $13.3 \%$ of the total genetic variation was due to unique allelic differences between the breeds, with the remaining $86.7 \%$ corresponding to differences among individuals within the breed across the 21 markers. All loci contributed to the differentiation with the highest values found for ETH225 (32.4\%). The pair-wise $\mathrm{F}_{\mathrm{ST}}$ values of breeds (Table 5) ranged between 0.007 to 0.261 , thereby revealing the least differentiation between Ponwar-Kenkatha (0.007), Bachaur-Gangatiri, Bachaur-Kenkatha (0.008), BachaurKherigarh, Gangatiri-Kenkatha, Kherigarh-Kenkatha, Kherigarh-Ponwar (0.009) and the highest divergence between Ongole and all other breeds of Northern India ( $>0.2)$. Similarly, AMOVA revealed that percent of variation among the populations was $24 \%$ while within the population it was $76 \%$.

Visualization of breed relationship was done by constructing Neighbor joining tree on the basis of Nei's genetic distance. As expected, the Ongole was most distinct and separated first, while remaining populations formed two groups with clustering of Hariana, Mewati and Gaolao on one node and all other north Indian breeds on second with more than $95 \%$ bootstrap value (Fig. 2). This grouping pattern was further supported by Principal Coordinate Analysis (PCoA). First three dimensions of the $\mathrm{PCoA}(\mathrm{PC} 1=44.59 ; \quad \mathrm{PC} 2=28.97 ; \quad \mathrm{PC} 3=10.88)$ accounted for $84.44 \%$ of total variation. Ongole was distinct from the rest of populations, Hariana and

Table 3 Variability of the mtDNA control region sequences of Indian cattle

\begin{tabular}{lllllll}
\hline $\begin{array}{l}\text { Cattle } \\
\text { population }\end{array}$ & $\begin{array}{l}\text { Number of } \\
\text { sequences }\end{array}$ & $\begin{array}{l}\text { Number of segregating } \\
\text { sites }\end{array}$ & $\begin{array}{l}\text { Number of } \\
\text { haplotypes }\end{array}$ & $\begin{array}{l}\text { Haplotype } \\
\text { diversity, } H_{d}\end{array}$ & $\begin{array}{l}\text { Average number of } \\
\text { differences }\end{array}$ & $\begin{array}{l}\text { Nucleotide } \\
\text { diversity, } \pi\end{array}$ \\
\hline Bachaur & 9 & 10 & 6 & 0.88889 & 2.55556 & 0.01131 \\
Kenkatha & 6 & 25 & 4 & 0.86667 & 8.60000 & 0.03805 \\
Kherigarh & 14 & 31 & 10 & 0.93407 & 5.96703 & 0.02640 \\
Ponwar & 8 & 13 & 7 & 0.96429 & 3.96429 & 0.01754 \\
Purnea & 26 & 38 & 20 & 0.95077 & 4.56308 & 0.02019 \\
Shahabadi & 31 & 33 & 15 & 0.89032 & 4.65806 & 0.02061 \\
Gaolao & 9 & 7 & 5 & 0.80556 & 2.38889 & 0.01057 \\
Hariana & 20 & 9 & 7 & 0.80526 & 2.14211 & 0.00948 \\
Mewati & 22 & 29 & 12 & 0.89610 & 4.89177 & 0.02165 \\
Ongole & 25 & 28 & 10 & 0.82000 & 12.10667 & 0.05357 \\
\hline
\end{tabular}


Table 4 Global F-Statistics for each of 21 microsatellite loci analyzed across 11 cattle populations

\begin{tabular}{|c|c|c|c|c|}
\hline Locus & Fis & Fit & Fst & $\mathrm{Nm}$ \\
\hline BM1824 & 0.144 & 0.188 & 0.051 & 4.632 \\
\hline CSSM08 & 0.025 & 0.143 & 0.121 & 1.820 \\
\hline CSSM33 & 0.011 & 0.076 & 0.067 & 3.508 \\
\hline CSSM66 & 0.018 & 0.052 & 0.035 & 6.851 \\
\hline ETH10 & -0.111 & -0.063 & 0.043 & 5.608 \\
\hline ETH225 & 0.014 & 0.333 & 0.324 & 0.522 \\
\hline ETH3 & -0.121 & 0.094 & 0.192 & 1.051 \\
\hline HEL09 & -0.037 & 0.117 & 0.149 & 1.427 \\
\hline HEL5 & 0.121 & 0.250 & 0.147 & 1.447 \\
\hline ILSTS06 & 0.153 & 0.223 & 0.084 & 2.743 \\
\hline ILSTS11 & 0.185 & 0.359 & 0.214 & 0.919 \\
\hline ILSTS34 & 0.096 & 0.167 & 0.078 & 2.950 \\
\hline ILSTS33 & 0.075 & 0.155 & 0.086 & 2.661 \\
\hline INRA05 & 0.019 & 0.168 & 0.152 & 1.395 \\
\hline INRA35 & 0.042 & 0.235 & 0.201 & 0.994 \\
\hline INRA63 & 0.054 & 0.208 & 0.163 & 1.284 \\
\hline MM12 & 0.087 & 0.117 & 0.033 & 7.359 \\
\hline MM8 & 0.083 & 0.262 & 0.195 & 1.030 \\
\hline TGLA122 & 0.091 & 0.120 & 0.032 & 7.532 \\
\hline TGLA227 & 0.060 & 0.341 & 0.299 & 0.586 \\
\hline TGLA53 & 0.013 & 0.131 & 0.119 & 1.848 \\
\hline Mean \pm SE & $0.049 \pm 0.017$ & $0.175 \pm 0.022$ & $0.133 \pm 0.018$ & $2.770 \pm 0.498$ \\
\hline
\end{tabular}

Mewati were closer and fall in a different quadrant along with Gaolao whereas, Kenkatha, Ponwar, Kherigarh, Gangatiri, Bachaur, Shahabadi and Purnea clustered together in one quadrant (Additional file 1: Figure S1). The results of the PCA are in concordance with the phylogenetic tree obtained in the present study (Additional file 1: Figure S1), with the first two components accounting for
$92.47 \%$ of the total variation among the populations. Likely value of $\mathrm{K}$ which best captures the variation present in the data following the Bayesian approach employed in software STRUCTURE was six based on modal value of $\mathrm{K}$ versus $\mathrm{K}$ distribution following Evano et al. [21]. Ongole, Gaolao, Purnea and Shahabadi were grouped in their own clusters. However, Hariana and Mewati animals partitioned into one cluster (Fig. 3). The results are coincident with genetic distance among the populations as divergence was lowest between Bachaur, Gangatiri, Kherigarh, Kenkatha and Ponwar (Additional file 2: Table S1). The assignment test based on likelihood method with the leave one out procedure [15] assigned $74 \%$ of the individuals correctly to their respective populations. All the individuals of Mewati, Gaolao, Hariana and all except one of Ongole and Shahabadi were assigned correctly, exhibiting distinctiveness of these breeds (Additional file 3: Sheet S1).

The overall pair wise comparison of mismatch distribution of mitochondrial sequences revealed a predominant peak at around 1 mismatch (pairwise differences). However, a minor peak at 22 and 24 mismatches was also observed (Additional file 4: Figure S2). The individuals from major group differed from each other by 1 to 7 mismatches, while the individuals from minor group differed by 20 to 29 mismatches. Phylogenetic relationship based on mtDNA haplotype revealed the clustering of breeds in two major clades, according to their geographic locations (Additional file 5: Figure S3). The breeds form northern/central regions were phylogeographically separated from Ongole breed of Southern region. The mtDNA haplotype data was further utilized to generate network using median-joining algorithm. The median network exhibited a complex network for haplotypes with two major star clusters indicating population expansion for Indian cattle (Fig. 4). This demography of population expansion was in accordance with the mismatch distribution.

Table 5 Fst estimates between each pair of eleven Indian cattle populations

\begin{tabular}{|c|c|c|c|c|c|c|c|c|c|c|c|}
\hline Bachaur & Gangatiri & Kherigarh & Kenkatha & Ponwar & Shahabadi & Purnea & Mewati & Gaolao & Hariana & Ongole & \\
\hline 0.000 & & & & & & & & & & & Bachaur \\
\hline 0.008 & 0.000 & & & & & & & & & & Gangatiri \\
\hline 0.009 & 0.010 & 0.000 & & & & & & & & & Kherigarh \\
\hline 0.008 & 0.009 & 0.009 & 0.000 & & & & & & & & Kenkatha \\
\hline 0.010 & 0.012 & 0.009 & 0.007 & 0.000 & & & & & & & Ponwar \\
\hline 0.032 & 0.031 & 0.032 & 0.034 & 0.032 & 0.000 & & & & & & Shahabadi \\
\hline 0.032 & 0.033 & 0.032 & 0.032 & 0.031 & 0.033 & 0.000 & & & & & Purnea \\
\hline 0.101 & 0.101 & 0.101 & 0.091 & 0.097 & 0.081 & 0.094 & 0.000 & & & & Mewati \\
\hline 0.052 & 0.057 & 0.054 & 0.050 & 0.051 & 0.042 & 0.050 & 0.062 & 0.000 & & & Gaolao \\
\hline 0.105 & 0.106 & 0.106 & 0.102 & 0.106 & 0.091 & 0.102 & 0.087 & 0.068 & 0.000 & & Hariana \\
\hline 0.212 & 0.210 & 0.213 & 0.213 & 0.212 & 0.203 & 0.206 & 0.257 & 0.201 & 0.261 & 0.000 & Ongole \\
\hline
\end{tabular}




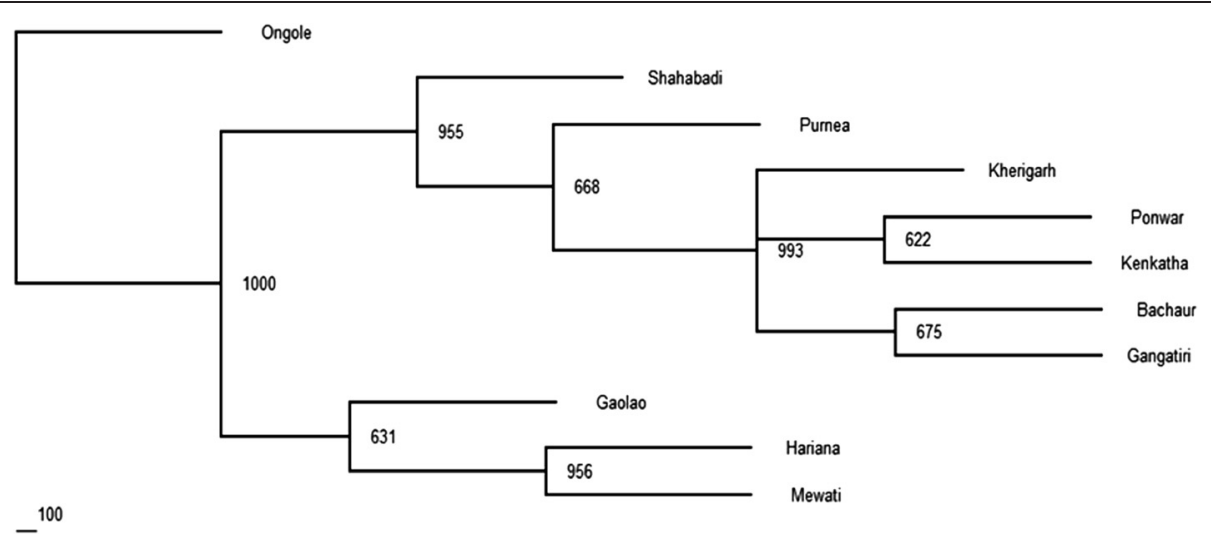

Fig. 2 Dendrogram (NJ) showing genetic relationships among eleven Indian cattle populations based on Nei's distance. The numbers at the nodes are bootstrap values from 1,000 replications

\section{Discussion}

Molecular information is crucial for preserving genetic diversity as well as preventing undesirable loss of alleles. In this study genetic diversity and population structure of Indian cattle was estimated using nuclear and mitochondrial DNA polymorphism.

\section{Genetic diversity of Indian cattle}

In general, genetic variation of the eleven populations is high according to the allele numbers and heterozygosity values of the microsatellite loci (Table 2) and the sequence divergence of mitochondrial hypervariable region-I (Table 3). The mean observed number of alleles across all the microsatellite loci were $8.784 \pm 0.25$ and were higher than other indigenous cattle breeds [28-30]. Lower allelic diversity than studied populations has also been reported in exotic cattle-Burlina-6.7 [31], Brown Swiss-5.4 [32] and Creole cattle-7.2 [33]. Previously also the allelic diversity in the Indian livestock breeds has been observed to be higher than that reported for the European counterpart [34]. This might be attributed to lack of artificial selection pressure and also indicates large effective population size of investigated Indian cattle populations. Allelic diversity of similar magnitude has also been reported in Tharparkar, Rathi and Orissa cattle populations of India [8, 12]. Measures of genetic diversity based on allelic richness are considered important in conservation genetics as marker-assisted methods for maximizing number of alleles conserved have been shown to be effective [35]. It is also relevant in longterm perspective, as selection limits are determined by the initial allelic composition rather than by heterozygosity [36].

Estimates of observed heterozygosity including all loci and population $(0.653 \pm 0.014)$ confirm the remarkable level of diversity in the studied populations. Higher genetic variation in Indian cattle must have contributed to its adaptability as genetic variation is necessary to allow organisms to adapt to ever changing environments with some of this variation stemming from introduction of new alleles by the random and natural process of mutation. Overall heterozygosity estimates were comparable with Tharparkar cattle (0.64) [8], Orissa cattle populations (0.62 to 0.66) [12] of India, Chinese cattle (0.62) [37] and Creole cattle (0.61) [33]. The least observed (0.459) and expected heterozygosity (0.594) values were detected for Ongole. The highest heterozygosity in Shahabadi population (0.735) could be explained by the occurrence of low selection pressure due to the lack of breeding programs. Similarly high mtDNA diversity as

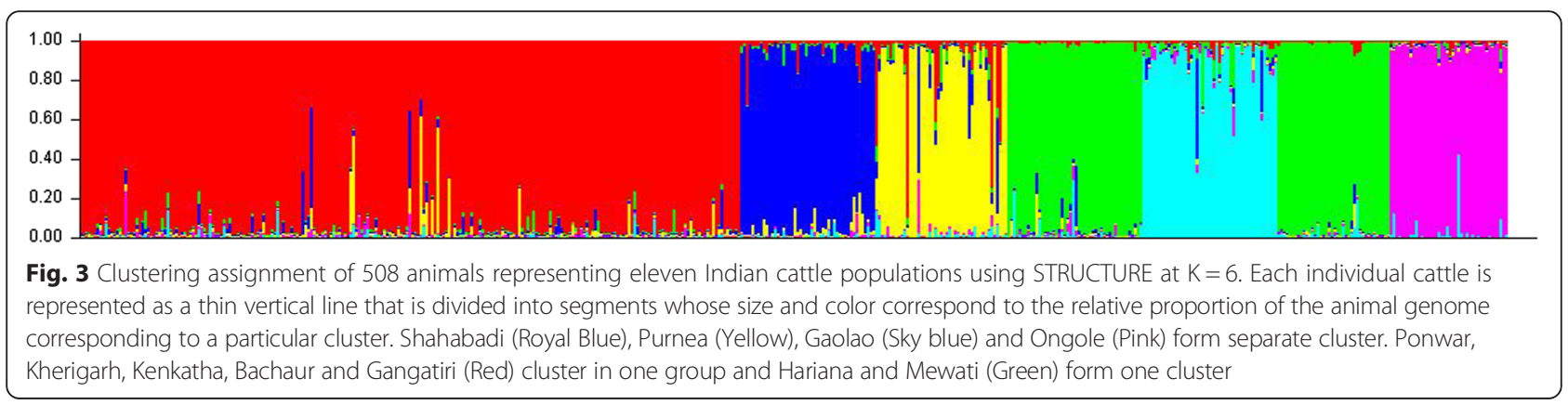




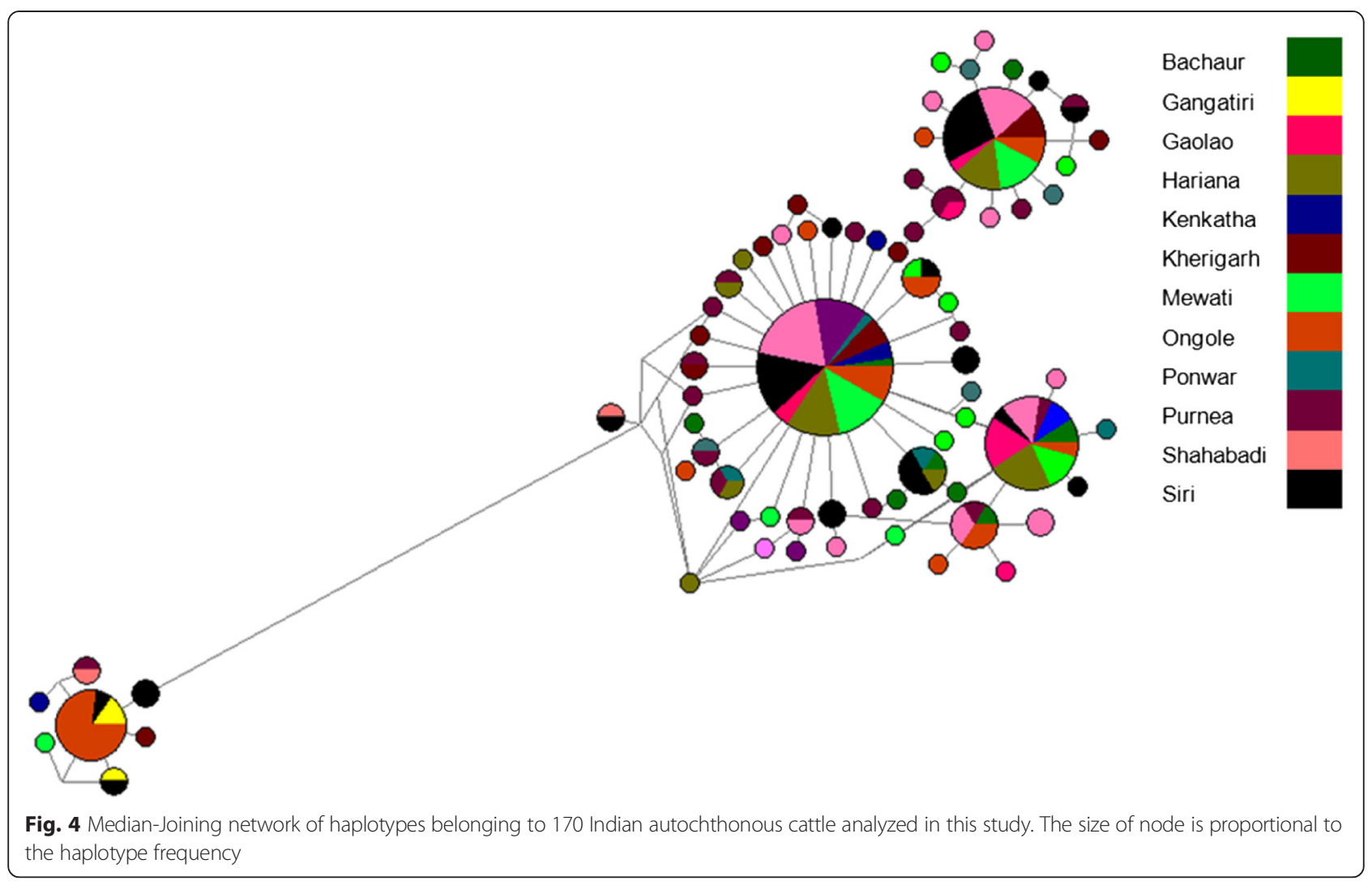

reflected in haplotypic $\left(\mathrm{H}_{\mathrm{d}}\right)$ and nucleotide diversity $(\pi)$ is also congruent with previous results of Indian cattle $[38,39]$. Higher genetic diversity of Indian cattle can be due to less emphasis on programmed breeding strategies. An additional source for increased indicine diversity could be the involvement of several species leading to admixture as suggested by Decker et al. [40] using genotypes from 43,043 autosomal single nucleotide polymorphism markers, scored in 1,543 animals involving high-throughput genotyping assays.

Significant heterozygote deficit $\left(\mathrm{F}_{\mathrm{IS}}\right)$ was observed for eight of the 12 breeds investigated being highest in Ongole (0.221). On the contrary, Kenkatha, Kherigarh and Gangatiri presented slight heterozygote excess in the population $(-0.028,0.002,-0.010$, respectively) which was expressed in heterozygosity pattern too (Table 2). These results can be interpreted as possible signs of outbreeding, most likely due to recent admixture of two (or more) populations. Free grazing of these animals with the non-descript animals in a herd could be the likely source for the excess heterozygotes. Positive $F_{I S}$ estimate for remaining populations indicates either the presence of inbreeding and /or Wahlund effect (presence of population substructure within breed). Since blood samples were collected from different villages, presence of a hidden substructure cannot be ruled out. Paucity of pure bulls as well as management seems to be the main reasons for heterozygote deficiency in these cattle. Moreover exotic/crossbred semen (Jersey and Holstein Friesian) is available in the breeding tracts whereas, local bull semen is usually unavailable to the owners. Together these two factors are resulting in the reduction of true to the breed type animals. In case of draft breeds, most of the males are used for carrying loads and agricultural operations. These males are castrated around the age of one year leading to their genetic death. With the modernization of agriculture and sub-division of land holdings, bullock power in Indian agriculture is losing its importance. Thus, with the diminishing demand for bullock power, the farmers are not adequately motivated to conserve these draft breeds.

\section{Differentiation between southern Indian and central and northern Indian populations}

The clustering solutions of nuclear and mitochondrial DNA showed extensive sharing of diversity and absence of genetic substructure between the geographically proximal populations and breeds. Our results showed that Southern Indian cattle (Ongole) and Central and Northern Indian cattle have distinctive genotypes, both in nuclear (Figs. 2, 3 and Additional file 1: Figuire S1) and in mitochondrial genomes (Fig. 4 and Additional file 5: Figure S3). 
The studied populations showed a moderate and significant genetic differentiation $\left(\mathrm{F}_{\mathrm{ST}}=0.133 \pm 0.018\right)$. These results reflect that within-breed genetic variation is more $(86.7 \%)$ than between-breed $(13.3 \%)$ and this variation could be a valuable tool for genetic improvement and conservation of cattle populations of India. Genetic differentiation of similar magnitude has been reported in some other indigenous cattle [9]. However, much lower $\mathrm{F}_{\mathrm{ST}}$ value has been reported among cattle breeds of Orissa and hill cattle of Kumaun (0.044) from India [12], as well as zebu cattle of Bangladesh [41]. While, several reports on exotic cattle (Bos taurus) viz. North European breeds $\mathrm{F}_{\mathrm{ST}}=0.107$ [42], seven European cattle breeds $\mathrm{F}_{\mathrm{ST}}=0.112$ [43] and Swiss cattle $\mathrm{F}_{\mathrm{ST}}=0.090$ [32] also depicted lower genetic differentiation than populations investigated in this study. The higher value of genetic differentiation in Indian cattle in this case may be attributed to the fact that the breeds are geographically well separated from each other being distributed in three different regions of India and the divergence is due to the reproductive isolation by distance. Similarly high genetic differentiation was observed by Mukesh et al. [28] with three Indian cattle which were far apart in distribution (Sahiwal, Deoni and Hariana). Furthermore, five lines of evidence suggest that Indian cattle breeds are differentiated. First, visualization of breed relationship using NJ tree obtained from Nei's genetic distance shows clustering of breeds in conformity to the geographic location of populations (Fig. 2). Secondly, these observations were supported by the PCoA, which graphically illustrated differentiation of Ongole from rest of Indian cattle and further differentiation of Hariana, Mewati and Gaolao from the remaining cattle breeds of Northern India (Additional file 1: Figure S1). Thirdly, assignment test could correctly assign individuals of five breeds. Fourthly, an alternative Bayesian approach followed to delineate clusters of individuals on the basis of their genotypes at multiple loci employed in software STRUCTURE illustrated strong genetic structure of the cattle population of south (Ongole) with respect to other cattle breeds. Graphical methods are loosely connected to statistical procedures for the identification of homogeneous clusters of individuals. Whereas, Bayesian clustering methods allow for the assignment of individuals to groups based on their genetic similarity and provide information about the number of populations underlying the observed genetic diversity. Lastly, the mutational dynamics of mtDNA sequences enable the genetic relationships among haplotypes to be inferred and also confirmed uniqueness of Ongole cattle. In totality, all the approaches confirmed that Ongole from South India formed its own distinct cluster.

These different lines of evidence suggest that some degree of genomic divergence has occurred between Ongole and other cattle breeds of India. The genomes of modern cattle basically reflect the history of animal movements by migratory farmers out of the ancient centers of the cattle domestication. At the time of Neolithic transition, zebu cattle were considered to be the most abundant and important domestic livestock species in Southern Asia. Indus Valley is the major centre of domestication for Indian cattle (Bos indicus) [40, 44]. However previous studies on Indian cattle have also proposed independent domestication centres (Indus valley, Ganges and South India) for Indian zebu (Bos indicus) $[38,45]$. In the current study too, the network constructed using median-joining algorithm exhibits two star like expansion events radiating from two ancestral nodes revealing distinct dichotomy between southern cattle (Ongole) and other Indian cattle encompassing large separation time. This demography is further supported by the mismatch distribution where two smooth, bimodal distributions were separated by a large time interval (Additional file 4: Figure S2). The analysis for Indian cattle mtDNA haplotypes indicates the distinctness among star clusters (major proportion from Northern/central region) and an ancestral node from southern region separated with large number of mutation events (Fig. 4). Overall, the Southern breed 'Ongole' was distinct with respect to breeds from Northern/ Central India. This is also in concordance with the phylogeography of the analyzed breeds. South India has also been proposed as another independent centre of domestication within south Asia, specifically for crops [46]. Moreover, the morphological differences between cattle depicted in the rock art of South India and in the iconography of Indus Valley civilizations have also lead to the suggestions that the South India was a secondary centre for zebu domestication [46]. Further, remains of wild aurochs (Bos primigenius) have been clearly identified from Banahalli, Karnataka (India) [46, 47].

The inferences obtained from nuclear (STRs) and mitochondrial (D-loop) markers are consistent and in agreement with geographical distribution and historical backgrounds. Both proved the clear genetic differentiation between southern and other Indian cattle breeds. However, clustering solutions of mitochondrial and nuclear DNA showed extensive sharing of diversity and absence of genetic substructure between the breeds and populations of a single geographic area. Further studies involving genome-wide approaches are apparently needed for further elucidation of differentiation.

\section{Conclusion}

This study involves detailed analysis of the genetic diversity and differentiation of Indian cattle from different regions. It is vital to report that indigenous cattle populations of India retain high levels of genetic diversity based on the results from analysis of two genetic markers (microsatellites and mtDNA control region). Inbreeding was detected in some 
breeds, suggesting the need for appropriate measures to be taken to avoid the negative effects. The results presented here can be used to assist all stakeholders as breeds with wide range of genetic diversity are required in the future for generating transgressive variation for quantitative loci mapping and developing new genotypes for particular management systems and market needs.

\section{Additional files}

Additional file 1: Figure S1. Two-dimensional plot of the Principal Coordinate Analysis (PCoA) and Principal Component Analysis (PCA), depicting relative position of eleven cattle populations.

Additional file 2: Table S1. Nei's genetic distance between each pair of eleven Indian cattle populations.

Additional file 3: Sheet S1. Assignment of individuals to their reference populations (sheet 1) and pairwise population assignment graphs (sheet2).

Additional file 4: Figure S2. Mismatch distribution constructed using mtDNA sequences analyzed for Indian cattle (Bos indicus) breeds in the present study.

Additional file 5: Figure S3. mtDNA haplotype based UPGMA tree depicting phylogenetic relationship among Indian cattle breeds.

\begin{abstract}
Abbreviations
DNA: Deoxyribonucleic acid; dNTPs: Deoxynucleotide triphosphates; EDTA: Ethylene diamine tetra acetic acid; FAO: Food and agriculture organization of the United Nations; $\mathrm{H}_{d}$ : Haplotype diversity; He: Expected heterozygosity; Ho: Observed heterozygosity; HVR-I: Hypervariable region-l; HWE: Hardy-Weinberg equilibrium; ICAR: Indian council of agricultural research; ISAG: International society for animal genetics; MCMC: Marcov Chain Monte Carlo iterations; $\mathrm{MgCl}_{2}$ : Magnesium chloride; Mitochondrial D loop: mitochondrial displacement loop; mtDNA: Mitochondrial DNA; NCBI: National centre for biotechnology information; Ne: Effective number of alleles; NJ: Neighbor-joining tree; No: Observed number of alleles; PCA: Principal component analysis; PCR: Polymerase chain reaction; SoW-AnGR: The state of the world's animal genetic resources; STRs: Short tandem repeats; UPGMA: Unweighted pair group method with arithmetic mean.
\end{abstract}

\section{Competing interests}

The authors declare that they have no competing interests.

\section{Authors' contributions}

RS participated in project conception, analysis and drafting the manuscript. AK and AM carried out genotyping. SA analyzed the mitochondrial polymorphism. AKP planned and collected the samples. MM was involved in data generation, MST helped in data analysis and writing final version of manuscript. All authors have read and approved the final manuscript.

\section{Acknowledgement}

The authors wish to thank the financial Support provided by Network Project on Animal Genetic Resources, Indian Council of Agricultural Research, India for carrying out this study. The assistance and contribution of State Animal Husbandry Department, Government of Uttarakhand, Government of Bihar and Government of Uttar Pradesh in the collection of blood samples from habitat of local cattle is duly acknowledged.

Received: 30 December 2014 Accepted: 22 May 2015

Published online: 30 June 2015

\section{References}

1. Livestock Census. BAHS-basic animal husbandry statistics: Department of Animal Husbandry, Dairying \& Fisheries, Ministry of Agriculture, Government of India. New Delhi: Krishi Bhavan; 2012.

2. FAO. The state of the world's animal genetic resources for food and agriculture. In: Rischkowsky B, Pilling D editors. Rome: Commission on
Genetic Resources For Food and Agriculture of the Food and Agriculture Organization of the United Nations; 2007

3. Barcaccia G, Felicetti M, Galla G, Capomaccio S, Cappelli K, Albertini E, et al. Molecular analysis of genetic diversity, population structure and inbreeding level of the Italian Lipizzan horse. Livest Sci. 2013;151(2-3):124-33.

4. Putman Al, Carbone I. Challenges in analysis and interpretation of microsatellite data for population genetic studies. Ecol Evol. 2014;4(22):4399-428.

5. Loftis DG, Echelle AA, Koike H, Van den Bussche RA, Minckley CO. Genetic structure of wild populations of the endangered desert pupfish complex (Cyprinodontidae: Cyprinodon). Conserv Genet. 2009;10:453-63.

6. Galtier N, Nabholz B, Glémin S, Hurst G. Mitochondrial DNA as a marker of molecular diversity: a reappraisal. Mol Ecol. 2009;18:4541-50.

7. Hoarau G, Piquet AM, Van der Veer HW, Rijnsdorp AD, Stam WT, Olsen JL. Population structure of plaice (Pleuronectesplatessa L.) in northern Europe, a comparison of resolving power between microsatellites and mitochondrial DNA data. J Sea Res. 2004;51:183-90.

8. Sodhi M, Mukesh M, Ahlawat SPS, Sobti RC, Gehlot GC, Mehta SC, et al. Genetic diversity and structure of two prominent Zebu cattle breeds adapted to the arid region of India inferred from microsatellite polymorphism. Biochem Genet. 2008;46:124-36.

9. Sodhi M, Mukesh M, Mishra BP, Ahlawat SPS, Prakash B, Sobti RC. Microsatellite analysis of genetic population structure of Zebu cattle (Bos indicus) breeds from North-Western region of India. Anim Biotech. 2011;22:16-29.

10. Sharma R, Pandey AK, Singh Y, Prakash B, Mishra BP, Kathiravan P, et al. Evaluation of genetic variation and phylogenetic relationship among north Indian cattle breeds. Asian Australs J Anim Sci. 2009;22:13-9.

11. Sharma R, Maitra A, Singh PK, Tantia MS. Genetic diversity and relationship of cattle populations of East India: distinguishing lesser known cattle populations and established breeds based on STR markers. Springer Plus. 2013;2:359. doi:10.1186/ 2193-1801-2-359.

12. Sharma R, Maitra A, Pandey AK. Genetic structure and differentiation of four Indian autochthonous cattle populations. Russian J Genet. 2012:48(6):611-7.

13. Sambrook J, Fritsch EF, Maniatis T. Molecular cloning: a laboratory manual. 2nd ed. New York: Cold Spring Harbour Laboratory Press; 1989.

14. FAO. Molecular genetic characterization of animal genetic resources. No. 9 Rome, repost: FAO Animal Production and Health Guidelines; 2011.

15. Peakall R, Smouse PE. A heterogeneity test for fine-scale genetic structure. Mol Ecol Notes. 2008;17:3389-400

16. Nei M. Molecular evolutionary genetics. New York: Columbia University Press; 1987.

17. Page RDM. TreeView: an application to display phylogenetic trees on personal computers. Comp App in Biosci. 1996;12:357-8.

18. Felsenstein J. PHYLIP: phylogeny inference package, version 3.5. Seattle, Washington: Department of Genome Sciences, Washington University; 1993.

19. Raymond M, Rousset F. GENEPOP: population genetics software for exact tests and ecumenicism. J Hered. 1995;86:248-9.

20. Pritchard J, Stephensa M, Donnelly P. Inference of population structure using multilocus genotype data. Genetics. 2000;155:945-59.

21. Evanno G, Regnaut $S$, Goudet J. Detecting the number of clusters of individuals using the software structure: a simulation study. Mol Ecol. 2005;14:2611-20.

22. Earl DA, vonHoldt BM. STRUCTURE HARVESTER: a website and program for visualizing STRUCTURE output and implementing the Evanno method. Conserv Genet Resour. 2012;4(2):359-61.

23. Suzuki R, Kemp SJ, Teale AJ. Polymerase chain reaction analysis of mitochondrial DNA polymorphism in Ndama and Zebu catle. Anim Genet. 1993;24:39-343.

24. Excoffier L, Laval G, Schneider S. Arlequin ver. 3.0: an integrated software package for population genetics data analysis. Evol Bioinform. 2005;1:47-50.

25. Tamura K, Stecher G, Peterson D, Filipski A, Kumar S. MEGA6: molecular evolutionary genetics analysis version 6.0. Mole Biol Evol. 2013;30:2725-9.

26. Bandelt $\mathrm{HJ}$, Forster $\mathrm{P}$, Rohl A. Median-joining networks for inferring intraspecific phylogenies. Mol Biol Evol. 1999;16:37-48.

27. Buchanan FC, Adams L, Littlejohn RP, Maddox JF, Crawford AM. Determination of evolutionary relationships among sheep breeds using microsatellites. Genomics. 1994;22:397-403.

28. Mukesh M, Sodhi M, Bhatia S, Mishra BP. Genetic diversity of Indian native cattle breeds as analyzed with 20 microsatellite loci. J Anim Breed Genet. 2004:121:416-24.

29. Pandey AK, Sharma R, Singh Y, Prakash B. Genetic diversity studies of Kherigarh cattle based on microsatellite markers. J Genet. 2006:85:117-22.

30. Pandey AK, Sharma R, Singh Y, Prakash B, Ahlawat SPS. Evaluation of genetic variation in Kenkatha cattle by microsatellite markers. Asian Australs J Anim Sci. 2006;19:1685-90. 
31. Dalvit C, De Marchi M, Dal ZR, Zanetti E, Meuwissen T, Cassandro M. Genetic characterization of Burlina cattle breed using microsatellite markers. J Anim Breed Genet. 2008;125:137-44.

32. Schmid M, Saipveaova N, Gaillard C, Dolf G. Genetic diversity in Swiss cattle breeds. J Anim Breed Genet. 1999;116:1-8.

33. Egito AA, Paiva SR, Albuquerque MM, Mariante AS, Almeida LD, Castro SR, et al. Microsatellite based genetic diversity and relationships among ten Creole and commercial cattle breeds raised in Brazil. BMC Genet. 2007:8:83-97.

34. Joshi BK, Sodhi M, Mukesh M, Mishra BP. Genetic characterization of farm animal genetic resources of India: a review. Indian J of Anim Sci. 2012;82(3):1259-75.

35. Bataillon TM, David JL, Schoen DJ. Neutral genetic markers and conservation genetics: simulated germplasm collections. Genetics. 1996;144:409-17.

36. Petit RJ, El Mousadik A, Pons O. Identifying populations for conservation on the basis of genetic markers. Conserv Biol. 1998;12:844-55.

37. Sun W, Chen H, Lei C. Genetic variation in eight Chinese cattle breeds based on the analysis of microsatellite markers. Genet Sel Evol. 2008:40:681-92.

38. Baig M, Beja-Pereira A, Mohammad R, Kulkarni K, Farah S, Luikart G. Phylogeography and origin of Indian domestic cattle. Curr Sci. 2005;89:38-40.

39. Bhuiyan MSA, Bhuiyan AKFH, Yoon DH, Jeon JT, Park CS, Lee JH. Mitochondrial DNA diversity and origin of Red Chittagong cattle. Asian Australas J Anim Sci. 2007;20:1478-84.

40. Decker JE, McKay SD, Rolf MM, Kim JW, Alcalá AM, Sonstegard TS, et al. Worldwide patterns of ancestry, divergence, and admixture in domesticated cattle. PLoS Genet. 2014;10:E1004254.44.

41. Uzzaman MR, Edea Z, Bhuiyan MSA, Walker J, Bhuiyan AKFH, Kim K. Genome-wide single nucleotide polymorphism analyses reveal genetic diversity and structure of wild and domestic cattle in Bangladesh. Asian Australas J Anim Sci. 2014;27(10):1381-6.

42. McHugh DE, Loftus RT, Cunningham P, Bradley DG. Genetic structure of seven European cattle breeds assessed using 20 microsatellite markers. Anim Genet. 1998:28:333-40.

43. Kantanen J, Edwards CJ, Bradley DG, Viinalass H, Thessler S, Ivanova Z, et al Maternal and paternal genealogy of Eurasian taurine cattle (Bostaurus). Heredity. 2009;103:404-15.

44. Zeder MA. Archaeozoology in Southwest Asia: a status report based on the eighth meeting of the Archaeozoology of Southwest Asia and Adjacent Areas Working Group. Pale'orient. 2006:32:137-47.

45. Chen S, Lin BZ, Baig M, Mitra B, Lopes RJ, Santos AM, et al. Zebu cattle are an exclusive legacy of the South Asia Neolithic. Mol Biol Evol. 2010;27:1-6.

46. Fuller DQ. Agricultural origins and frontiers in South Asia: a working synthesis. Journal of World Prehistory. 2006;20:1-86.

47. Korisettar R, Venkatasubbaiah PC, Fuller DQ. Brahmagiri and beyond: the archaeology of the Southern Neolithic. In: Settar S, Korisettar R, editors. Indian archaeology in retrospect. New Delhi (India): Manohar Press; 2001. p. $151-237$.

\section{Submit your next manuscript to BioMed Central and take full advantage of:}

- Convenient online submission

- Thorough peer review

- No space constraints or color figure charges

- Immediate publication on acceptance

- Inclusion in PubMed, CAS, Scopus and Google Scholar

- Research which is freely available for redistribution 